\title{
Balancing a Sphere in a Linear Oscillatory Movement through Fuzzy Control
}

\author{
Gustavo Ozuna, German Figueroa \\ Department of Industrial Engineering and Systems \\ University of Sonora \\ Hermosillo, Mexico
}

\begin{abstract}
The following paper describes an intelligent control problem, which depends on the balance of a metallic sphere on a beam, that oscillates in only one point, localized in the middle of the beam, using it for the balance of this fuzzy control system.
\end{abstract}

Keywords-ball beam system; balancing a metallic sphere; inclination; equilibrium forces.

\section{INTRODUCTION}

There exist several problems with the control of electromechanical and mechatronics systems, for example the inverted pendulum [1], which solution has been approached from various methodologies, another example is the braking of a vehicle at high speed, the direction and the detection of obstacles, this is why the following control problem is proposed, which consist in balancing a metallic sphere on a beam with linear oscillatory movement, at a supporting point located in the center as shown in figure 1, in which the sphere will experiment several positions changes in an unstable form losing balance, for the control system handle the stabilizing of the sphere in the center, the fuzzy control is used.

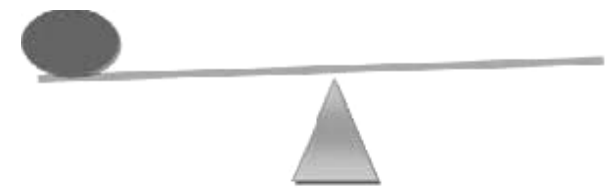

Figure 1. Balancing a sphere over the beam

\section{PROBLEM}

The following problem is to success the balance of a sphere on a beam which has the point of support in the center, when the sphere travels form right to left and left to right, makes the beam lose the balance, currently there are several similar problems called ball beam system [2].

This system consists in slope a beam, in which a metal sphere travels, searching the right inclination to achieve the same position of another sphere that is in constant movement outside the system.

The system uses a distance sensor which provides the information to take the right inclination of the beam to place the sphere at the same position as the reference sphere that is in constant movement, unlike the previously cited this only includes one sphere.

\author{
Marek Wosniak \\ Politechnika Lodzka, \\ Poland
}

\section{PROTOTYPE}

To control the inclination of this system a direct current motor is connected to the center of the beam, which rotates the beam form left to right and right to left, as appropriate to achieve the balance of the sphere, taking the signal of a sensor of inclination as shown in figure 2 .

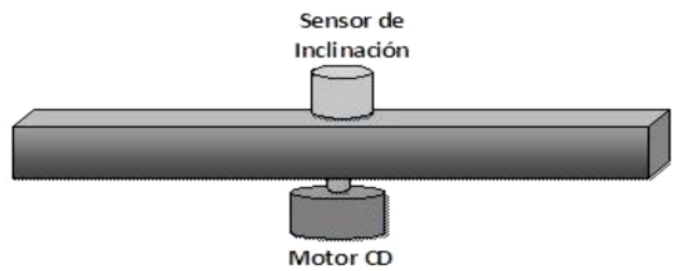

Figure 2. Direct current motor and

The leaver system in which the sphere moves freely is represented by the next equations, such as the Torque Moment and the equilibrium forces on the beam:

$$
\begin{aligned}
& F_{N}-F_{A}-F_{B}=0 \\
& M=F d \\
& F=m g
\end{aligned}
$$

In which $\mathrm{F}_{\mathrm{N}}$ is the upward force of the supporting point and $F_{A}$ and $F_{B}$ are the forces that the sphere exercises when it moves and $\mathrm{M}$ is the Torque that are changing according to the distance of the sphere from the pivot [4] as shown in figure 3 .

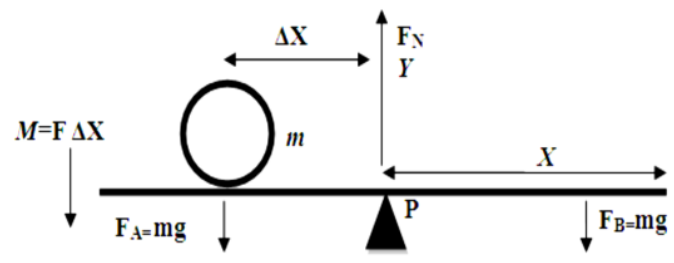

Figure 3. Forces that interact with the system

\section{CONTROL}

The fuzzy control system is proposed for the system, which will emulate the human reasoning, in the system structure is identified the logic flow fuzzy inference of the input variable inclination with respect of the output variables direction and speed, the fuzzy inferences [6], the figure 4 shows the control system structure showing the analogical inputs, the block of fuzzy rules as the analogical outputs, the 
lines that connect symbolizes the flux of data simulated in the simulator FuzzyTech.

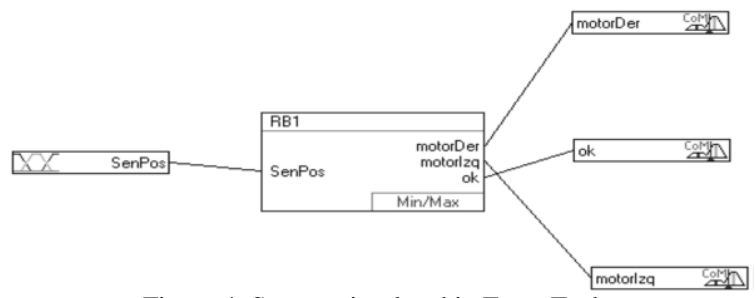

Figure 4. System simulated in FuzzyTech

The linguistic variables used in the system translates the real values of the position sensor into linguistic values and also into the outputs of the system shown in the table 1 and 2 .

TABLE 1. INPUT VARIABLE

\begin{tabular}{|l|l|l|l|l|l|l|l|}
\hline & Variable Name & Type & Unit & Min & Max & Default & Term Names \\
\hline 1 & SenPosicion & $\mathrm{X}$ & Units & 0 & 1 & 0.5 & $\begin{array}{l}\text { extremol } \\
\text { mediol } \\
\text { Bajoi } \\
\text { ok } \\
\text { bajoD } \\
\text { medioD } \\
\text { extremoD }\end{array}$ \\
\hline
\end{tabular}

Table 2. Output Variables

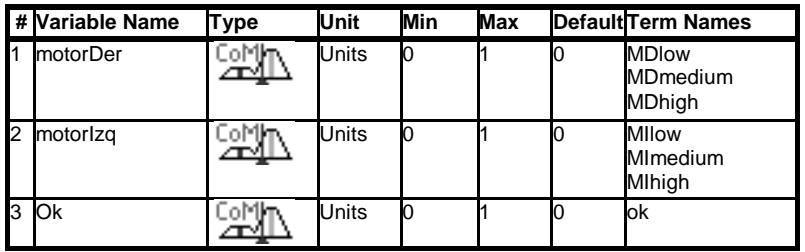

The fuzzy conjunct shown in the figure 5 shows the position sensor input using linguistic variables related to the right or left extreme of the leave like this until arriving the central position, place that is search to place the sphere accomplishing balance.



Figure 5. Fuzzy conjunct of input

The outputs of the system represented in the fuzzy conjunct of the figures $6,7,8$ shows how the direct wire motor should behave, the spin direction, as well as the signal that presents when the system is balance.

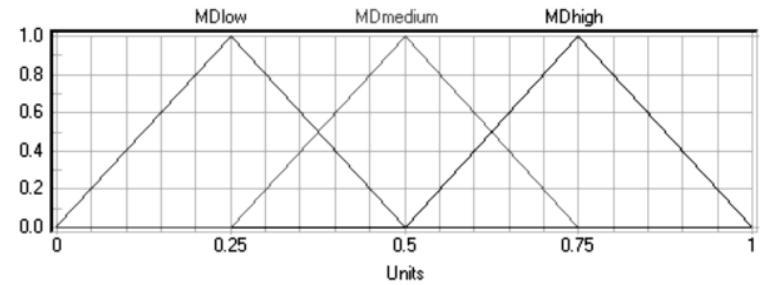

Figure 6. Fuzzy conjunct of output right to left motor

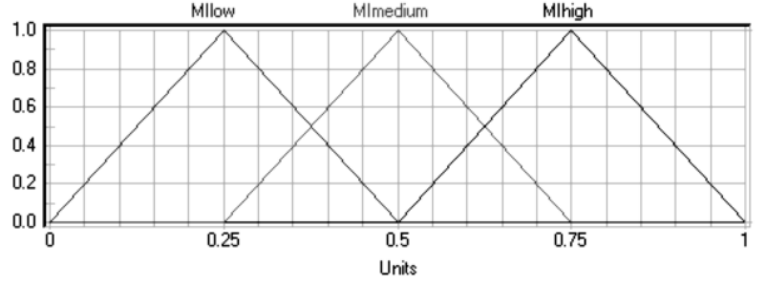

Figure 8. Fuzzy conjunct of output left to right motor

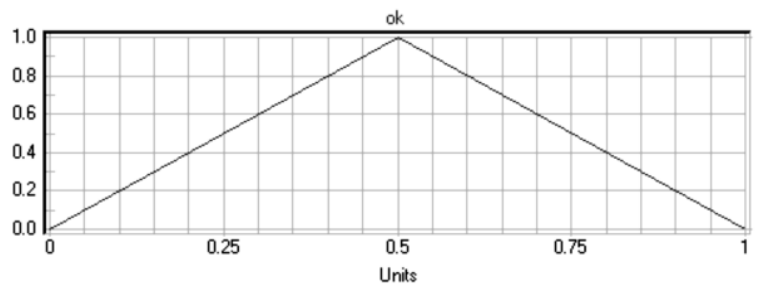

Figure 9. Fuzzy conjunct of output of the motor ok

The block rules shows the strategy for the control of the fuzzy system, the context is defined by the same variables of input and output operated by the maximum and minimum method shown in the table 3 .

TABLE 3. FUZZY RULES

\begin{tabular}{|l|l|l|l|l|l|l|}
\hline SenPos & DoS & motorDer & DoS & motorlzq & DoS & ok \\
\hline extremol & 1.00 & MDhigh & & & & \\
\hline mediol & 1.00 & MDmedium & & & & \\
\hline Bajoi & 1.00 & MDlow & & & & \\
\hline Ok & & & & & 1.00 & ok \\
\hline bajoD & & & 1.00 & Mllow & & \\
\hline meidioD & & & 1.00 & Mlmedium & & \\
\hline extremoD & & & 1.00 & Mlhigh & & \\
\hline
\end{tabular}

The behavior of the dc motor and sensor following the linguistic strategies to balance the sphere on the beam are shown in the figures 10 and 11.

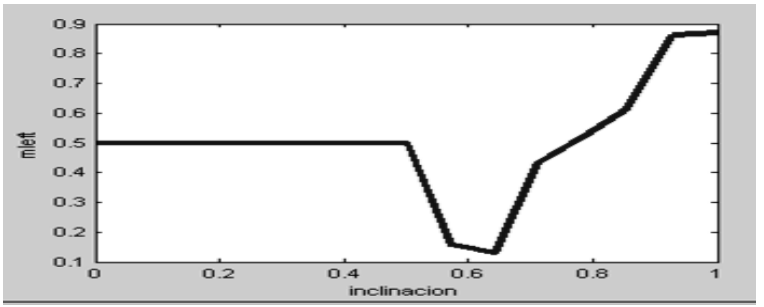

Figure 10. Fuzzy conjunct of output of the motor ok

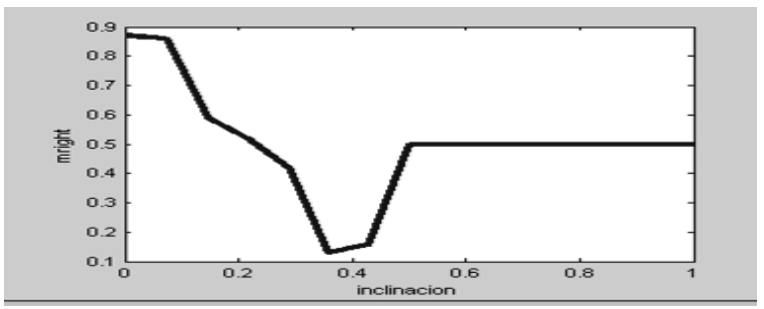

Figure 11. Fuzzy conjunct of output of the motor ok 


\section{ELECTRONIC PROPOSAL}

The position sensor, that it is proposed for the following system, consist of a variable resistant which is connected to two operational amplifiers configured as comparators, the circuit will provide the sense of inclination by the differential of voltage, shown in figure 12.



Figure 12. Circuit of the inclination sensor

The proposed system uses a microcontroller, 16F684A in which the fuzzy rules are programmed, this possess four analog inputs which connects the inclination sensor and the outputs for the direct wire motor in an array of transistors $(\mathrm{H}$ Bridge) to control the spin of it, to stabilize the beam.

\section{CONCLUSIONS}

The research of new methods of solution for electromechanical problems, help to put into practice the knowledge of intelligent control into the solution of Mechatronic systems, it is expected that this type of control problems may be helpful for other investigators to put in practice the different types of intelligence control.

\section{REFERENCES}

[1] Ogata K. "Ingeniería de Control Moderna", Pearson, España, 4ta Ed. 2003

[2] Bazañes L. "Control Digital”, UPC, España, 1ra Ed. 1994. Hewit P. "Física Conceptual”, Pearson, 9na Ed, 2004.

[3] Giancoli D. "Física”, Pearson, 6ta Ed. México, 2006.

[4] Alvarez L. "Fundamentos de Inteligencia Artificial", Universidad de Murcia, 1ra. España, 1994

[5] Xafha F. "Programación en C++ para Ingenieros", Paraninfo, 1ra Ed. España, 2006.

[6] Spartacus C. "Teoria de Control”, Alfa omega, 1ra Ed. España, 1999

[7] Alciatore D. "Introducción a la Mecatrónica", McGraw-Hill, 3ra Ed. México, 2008.

\section{AUTHORS PROFILE}

Gustavo Ozuna he is a robotics and electronics professor, in University of Sonora Mexico.gozuna@industrial.uson.mx

Marek Wozniak he is a professor in Lodz University of Technology, Department of Vehicles and Fundamentals of Machine Design, Poland.

German Figueroa, he is a industrial engiener student in the University of Sonora Mexico. 